DOI: 10.21005/pif.2021.46.C-06

\title{
STRATEGY OF DEVELOPMENT COASTAL AREAS IN A BIG CITY
}

\author{
Yevheniia Samoilenko \\ Author's Orcid number: 0000-0003-2813-4767
}

Assistant. Department of Architectural Design and Urban Planning

Prydniprovsk State Academy of Civil Engineering and Architecture

\section{ABSTRACT}

The article proves that a systematic approach to the urban organization of coastal areas includes complex environmental and recreational tasks. The study examines in detail the need to create a comprehensive strategy for the restoration of the coastal zone. The complex of measures is substantiated, among which the activation of water protection functions of coastal areas, rehabilitation of disturbed territories, use of recreational and town-planning potential of coastal territories for formation of recreational base along water area, development of integrated system of management of processes of coastal zones and integration of ecosystems.

The work separately highlights the possibility of creating a recreational cluster that will ensure the continuity of the natural framework, given the multi-vector formation of the urban environment. It is established, that the connection of the recreational cluster with the suburban green strip and water area will create a pedestrian recreational corridor in the city and beyond, as well as contribute to the greening of the city and influence the modeling of ecological infrastructure.

Key words: riparian areas, water diameter, recreational framework, revitalization, ecological cluster. 


\section{INTRODUCTION}

Features of recreational use of urban areas, in particular the formation of landscape structure and integrated system of landscaping of the coastal area in relation to the water area, the creation of water-green diameters, revitalization of river valleys, the formation of individual water-green objects, clustering - notable modern urban trends many cities around the world are still not sufficiently implemented in the cities of Ukraine. World experience confirms that a systematic approach to the urban organization of riparian areas includes complex environmental and recreational tasks: management of surface runoff within the catchment; protection of territories from flooding and flooding, which can be implemented in particular in a landscape way. These processes are confirmed by the relevant planning documents, but have not yet become widespread.

Solving the functional and planning needs of the city and the architectural and landscape organization of recreational spaces in its structure is complicated by the peculiarities of the river landscape and its interaction with the urban environment (Bilokon Yu., 2019, p. 200). There is a need to find new contact areas and sustainable models of interaction between urban and natural environments. The issue is transformed and considered in the plane of sustainable development with the formation of ecologically sustainable cultural landscapes of riparian areas in the city structure (Samoilenko Y., 2014, p. 462). The dialectical contradiction of the development of theoretical approaches and strategies for the formation of contact zones between the city and the water area is in the field of "dialogue of two elements" (Gelfond A., 2017, p. 137). The organization of the interaction of urban and natural is based on the concept of symbiosis. One of the directions of possible structuring and content of recreational space is in the plane of multilevel spatial, visual and compositional interactions of water area, river space and urban environment. At the same time, there is a need to form an appropriate comprehensive strategy for the development of riparian areas, taking into account the unique set of tasks and factors inherent in a particular urban environment.

Goal. To analyze the features of recreational use of riparian areas in modern urban conditions and provide practical recommendations for the formation of a strategy for the development of riparian areas on the example of the city of Dnipro.

The scientific and methodological basis for the study were scientific works on the recreational use of coastal areas. These are the works of the scientific school T. Panchenko (Panchenko T., 1983. p.101), Yu. Bilokon (Bilokon Yu., 2003, p. 246), V. Vadimov (Vadimov V., 2000, p. 214), V. Nefedova (Nefedov V., 2002. p. 295 p.), L. Ruban (Ruban L., 2020. p. 26). Scientific works and project experience in the field of urban planning were taken into account, in particular the study of the urban environment of the city of Dnipro in the project proposals concept of urban development, as well as materials to the city master plan: zoning scheme, project amendments to the master plan (Bilokon Yu., 2003, p. 226). Research in the field of renovation of industrial coastal areas of the city of Dnipro was taken into account separately (Merilova I., 2020, p. 384).

\section{PROBLEMS AND TERMINOLOGY OF RESEARCH}

Dialectical contradiction in the system "city-water area". The presence of water in the urban structure is of great value, both in terms of visual perception and comfortable living of its inhabitants, and in terms of the ecology of the urban environment. Acquisition of qualitatively new content in the interaction of man and nature can be realized under the conditions of providing territorial-spatial and urban processes of culturological content (Vadimov V., 2000, p. 214).

Thus, the issue of functional orientation on landscape reconstruction of territories along the waters of large rivers is actualized in a number of scientific works that were included in this study. According to them, the analysis of the existing functional use of the coastal zone of the city of Dnipro showed that residential buildings, as well as public and industrial zones occupy up to $80 \%$ of the area of all developed river areas. According to the sum of factors, the location of residential buildings near the central zone of the city gives a greater economic effect from the use of the territory than the formation of recreational complexes, but contradicts the need for green spaces. 
Today, the rational use of territorial resources is one of the most important tasks in the field of urban planning. In most cases, improving the quality of the urban environment is due to the need to develop a system of reconstruction measures and principles of architectural and landscape organization of the territory, which should be part of a long-term program of development of areas along the water area.

Modern urban planners and landscape architects such as Patrick Bushan and Gilles Clema record the mechanisms of the formation of abandoned or inefficient urban areas within the city. The emergence of such zones is inherent in the process of urbanization and is important from an ecological point of view. The so-called "landscapes of the third order", despite the insufficiently active role in the life of the city, are of great importance in the formation of the urban structure (Secchi B., 2006, p. 132).

Aware of the need for sustainable development, the entire urban system and urban policy in European countries began to focus on the interaction and coordinated functioning of economic, social and environmental factors (Paris R., 2000, p. 20). In particular, there are clear trends: to the compact development of cities, the preservation of the "green belt", the integration of "wildlife" into the urban environment, the expansion of biodiversity, landscaping of abandoned and revitalized former industrial areas.

According to the research of Bernard Seschi, the nature of the process of transformation of the territory reflects the traditions of urbanism of a particular country. Despite the fact that it is not easy to talk about the presence of a "natural component" in cities, the most unexplored aspects of the interaction of urban and landscape areas, their ability to develop, synergy and transformation. Riverside areas within the city act as a buffer between the city and the water area. Their main function is to ensure the interaction of natural and anthropogenic frameworks of the urban area. Creating such a unique zone in the city involves the appropriate urban transformation. The problems, strategic goals and results obtained in measuring this process require further rethinking (Vadimov V., 2000, p. 84).

The space within the water area is the basis for the formation of water-green diameter, and is an element of the natural framework of the city. (Fig. 1). Thus, renovation within the water area should include a comprehensive approach to the organization of the ecological framework of the city, optimization of the system of functional zoning of its territories, saturation of these areas with "green zones" and the formation of ecologically balanced environment.

Investigating the location of architectural objects and the organization of recreational spaces in the river area, it is possible to analyze the degree of involvement of the river space in the urban structure and the formation of its recreational framework.

Fragments in the structure of the river zone were identified for the city of Dnipro, their functional content, accessibility and nature of landscaping were analyzed. The fragmentary character of riverside urban ensembles, which are interspersed with industrial zones that break the line of perception, is noted. The riparian territories of the Dnieper, in the conditions of a post-industrial city, need at the same time to build a balanced relationship with radical reconstruction and a balanced strategy of use. The strategy should be guided by certain requirements for the implementation of renovation measures, which include: activation of water protection functions of river areas; rehabilitation of disturbed areas; use of recreational and urban potential of riparian areas for the formation of a recreational framework along the water area; integration of eco-clusters into the structure of riparian areas and development of an integrated process management system.

Activation of water protection functions of river areas. Great importance in the greening of the city is given to the formation of its ecological infrastructure, an integral part of which is the system of greenery and the water area of the city, which comprehensively form a natural recreational framework. This is a system of natural type, which provides the creation of appropriate, from an ecological point of view, living conditions in the city, allows the continuity of the natural framework in the city and forms a connection with suburban recreational areas (Fig. 1). 


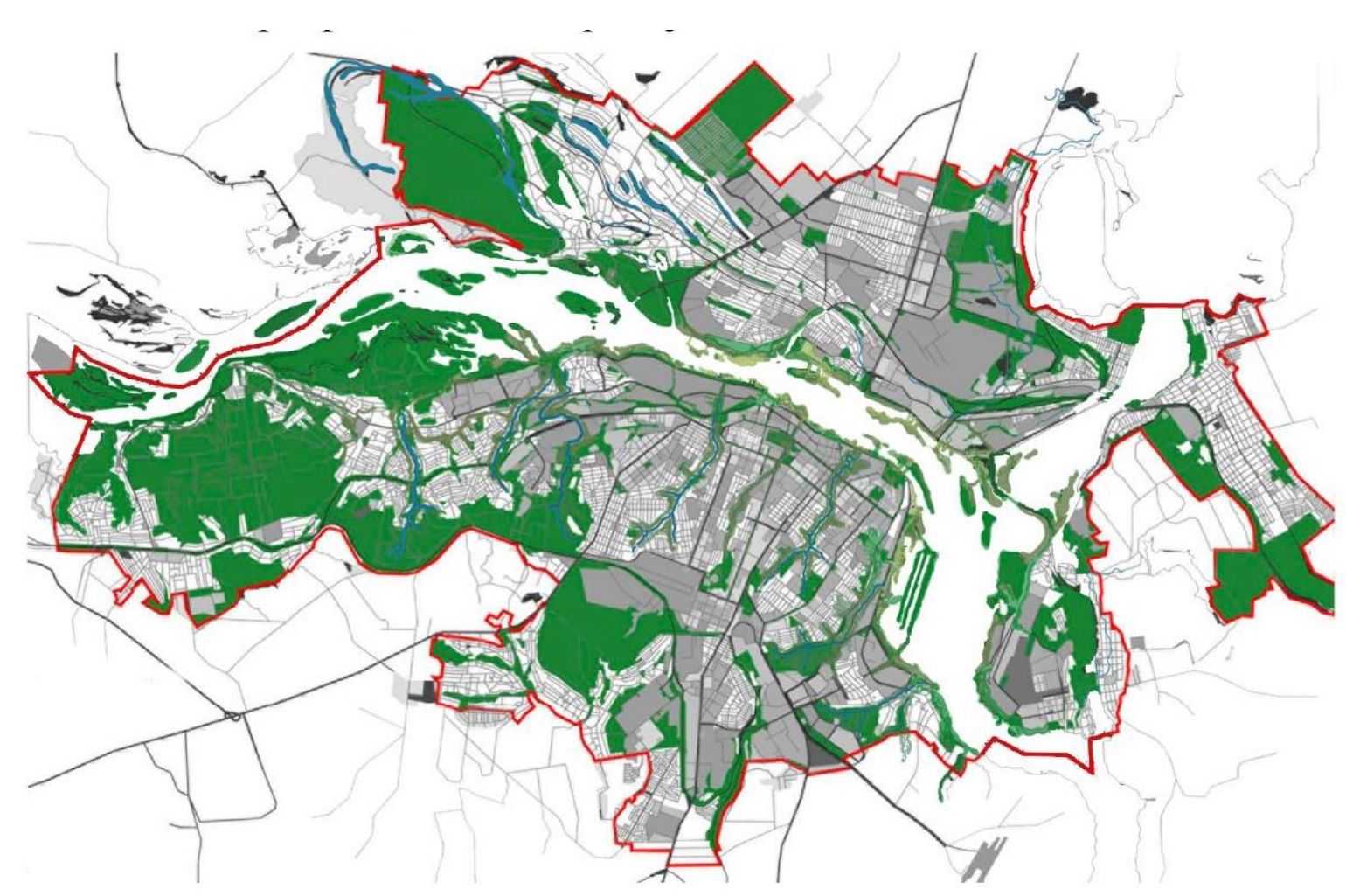

Fig. 1. Identity of recreational frame of the city . Source: These is author scheme

The methodology of spatial-functional formation of the urban environment in the water area takes into account the transformation of the coastal zone into a spatial-thematic scenario together with the need to integrate the entire number of local urban planning tasks. Analysis of possible vectors of river space development within the city with the formation of a contact zone in its structure, as a tool for project modeling, makes it possible to regulate the structural components of buildings and landscaping within the water area, creating a contact area with meaningful levels of interaction of river areas (Bilokon Yu., 2003, p. 54).

Rehabilitation of riparian areas, which means a set of measures within the riparian area, contributes to the territorial restoration and implementation of the principles of ecological sustainability, humanization and social orientation of the environment, maintaining the balance of natural and anthropogenic components of urban landscape and recreational needs of urban population. In this period of development, riparian areas are functionally rich and urbanized space. The study of the development of the territorial-spatial structure of cities in relation to the water systems allowed to determine that the riparian areas are prone to varying degrees of urbanization, some of them need renovation and replacement.

One of the main goals of the reconstruction projects is to determine approaches to the transformation of the landscape system of the city of Dnipro into an efficient and stably functioning urban framework. However, many aspects related to the forms of urban landscape transformation and natural forms in terms of their spatial characteristics and role in shaping the composition of the city, as well as the process of forming the ecological and urban framework and the organization of open spaces remain unclear. 
Thus, the master plan, as a regulatory document, should determine the path of transformation of the urban environment in the direction of the vector of sustainable innovative development of the territory on the basis of the introduction of a new structural element of the natural complex.

Formation of the system of ecological river corridor along the water area. Holistic strategy of ecological rehabilitation and aesthetic harmonization of the environment of the riparian zones means the transition from private, fragmentary implementations to the complex structure of the riparian urban environment. The main elements of the system are transverse connections, as a way of forming the contact zone of the river and the city. The study found that the presence of convenient communication links between the city center and the river area is the key to maximum integration of disparate, separate areas. Thus, according to the basic concept, building elements, green areas and water areas harmoniously flow into each other and form a single space and complex urban form due to the introduction of eco-cluster as an independent landscape-ecological element (Fig. 2).

Cluster in urban planning is understood as a territorial formation within the metropolis. It is a relatively autonomous unit and provides its residents with a full set of urban functions (residential, administrative and business, shopping and entertainment, recreation). Thus, the combination of several homogeneous elements can be considered as an independent unit with certain properties (Milkina I., 2007, p.61).
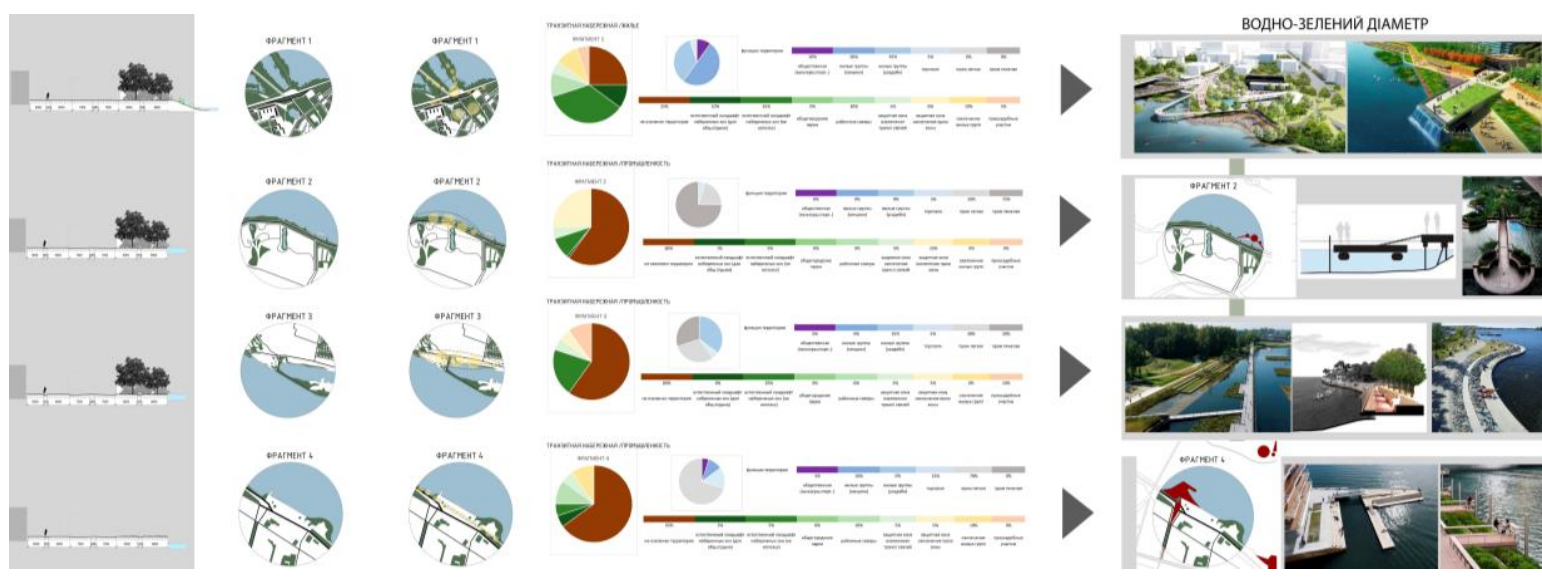

Fig.2 Analysis of fragments 1-3 of the river zone in the structure of the city. Coastal transformation strategies. Source: These are author scheme and diagrams

Also, the cluster in the urban environment is understood as a group of environmental spaces, united by innovative communication channels and infrastructure component, and represents, from the point of view of the city resident, a single urban resource (Milkina I., 2007, p.61).

Thus, a cluster is understood as a connected set of urban spaces that work together to perform the functions of the city system. Previously, clustering was mainly used in the economic sphere, but the study proposed to consider the integration of the cluster, as an element of landscape architecture, in the structure of the river area to create a holistic recreational space along the waters of a large river. 
Thus, the landscape approach in the creation of eco-clusters will be used as a method of reorganizing the environment by introducing nature into the urban space in order to form elements of green infrastructure. Components of the structure of riparian areas will now be: complex environmental ensembles, groups and single dominant objects, engineering structures, background objects.

In the course of the research it was established that the structural components of the landscape of urban water area are landscape features of the terrain, geoplasty of relief, nature of landscaping, as well as planning parameters, features of the configuration of the water area and its coastline.

These provisions allow to form the types of contact spaces within the river areas, as a set of several levels of dialogic interaction: functional, spatial, compositional, visual, plastic, historical and cultural. Eco-clusters can become such contact spaces in the urban environment.

Eco-cluster is formed as part of a single landscape-recreational form of the city, consisting of individual local elements of this form: parks, tree quarters, green areas, squares, boulevards, alleys, esplanades, islands, water gardens, etc. The cluster is an element for the formation of landscape architecture and creates conditions for green construction by maintaining a favorable microclimate: humidity, temperature, mobility of air masses, reducing the load on urban infrastructure and restoring landscaping.

In scientific work, the eco-cluster is considered as part of the urban green area, undergoing a period of rehabilitation to increase the percentage of green spaces in its structure, or as a recreational element formed on the water to provide a continuous recreational pedestrian corridor comfortable environmentally sustainable urban environment. Such clusters can become connecting elements between existing green zones. Thus, a multi-complex urban "multifunctional puzzle" is formed with the priority of creating and developing social and recreational areas overlooking the Dnieper.

Integration of eco-clusters into the structure of riparian areas. Changing the quality of the urban environment in the direction of the vector of sustainable development of the territory is possible on the basis of the formation of principles and methods of rehabilitation of riparian urban areas.

Significantly increase the level of innovation activity will allow the use of cluster approach in the formation of recreational corridors along the water area, introducing technopark structures replacing industrial areas, creating tourist and recreational areas as poles of economic growth, forming communication spaces, sustainable recreational ecoclusters. One of the approaches to the restoration of industrial areas is their ecological rehabilitation: reclamation of areas covered by the pollution zone; transformations within the transport infrastructure: bicycle connections, development of high-speed rail transport, organization of communication complexes within the embankment.

Development of a system of integrated process control in the riparian zone. On the one hand, uncontrolled self-filling of urban areas with natural elements affects the overall balance of green areas in cities, on the other hand, provokes social and urban conflicts. This property of "uncontrolled landscaping" of urban areas allows urban policy to assess the reserves of environmentally friendly development. For example, the Open Space Strategy, launched in the United Kingdom, officially regulates the use of river water protection zones as corridors of an ecological urban framework. This strategy also considers the small but important "green islands" between houses and along roads as "informal natural areas", which also play a role in shaping the system of open urban spaces. The main thesis is the fact that riverside areas need a special approach and strategy to manage their development without harming the environment. In international practice, the approach of integrated coastal zone management was established in 1996 by the European Commission, it is called "Integrated Complex Zone Management" ("ICZM" / "KUPZ"). The overall goal of the management process is to introduce into the practice of sustainable development the conservation of coastal areas together with the support of their biodiversity and is aimed at the balanced use of the coastal zone and human control within the territory (Order of the Cabinet of Ministers of Ukraine, 2007, p. 43). 


\section{CONCLUSIONS}

The presented approach is able to create a methodological basis for theoretical and design architectural and spatial modeling of riverside buildings at the stage of its new formation or reconstruction. It is established that the water area in the planning structure of the city is perceived as a linear object, a contact zone of multilevel visual and compositional interaction of the city water area with the coastal architectural development. It is determined that the functions of the contact zone allow to consider it in two aspects: as an effective tool for integrated monitoring of the natural, anthropogenic and cultural landscape of the water area, as well as a working tool for conceptual and project modeling.It is established that the main component of the ecological infrastructure of the city is the natural framework, the system of greenery and the water areas of the city. The formation of a recreational cluster in this system will ensure the continuity of the natural framework, taking into account the versatility of its formative structure. The connection of the recreational cluster with the suburban green belt and the water area will contribute to the formation of a single pedestrian and recreational system both in the city and outside it.

\section{BIBLIOGRAPHY}

Bilokon Yu. M. Regional planning. Theory and practice. Kyiv: Logos, 2003. $246 \mathrm{p}$.

Vadimov V. M. City and river (planning aspects). Poltava, 2000, p. 214.

Making changes to the master plan of the city. Section "Environmental Protection (Strategic Environmental Assessment Report)" Ministry of Regional Development, Construction and Housing of Ukraine, State Enterprise "Ukrainian State Research Institute of Urban Design" DIPROMISTO "named after Yu.M. Bilokon", Kyiv. 2019, 64 p.

Making changes to the general development plan of the city of Dnepropetrovsk. Explanatory note. Ministry of Regional Development, Construction and Housing and Communal Services of Ukraine, State Enterprise "Ukrainian State Research Institute of Urban Design" DIPROMISTO "named after Yu.M. Bilokon", Kyiv. 2019, $206 \mathrm{p}$.

Gelfond A. L. City by the river. Identical and global. Volga Scientific magazine. 2017. pp. 137-141.

Merilova I. Comprehensive assessment of the urban-ecological condition of the Dnieper city. Problems and solutions. Urban planning and spatial planning: scientific and technical. zb. KNUBA. Kyiv, 2020. Issue. 70.S. 384-393.

Milkina I.V. Theoretical bases of formation of strategy of innovative development of territories. Innovations, № 10, 2007. P. 81.

Nefedov V.A. Landscape design and environmental stability. St. Petersburg: Poligrafist, 2002. 295 p.

Panchenko T.F. Design of resorts and recreation areas. Kiev: Builder, 1983. $101 \mathrm{p}$.

Order of the Cabinet of Ministers of Ukraine "On approval of the Concept of national environmental policy of Ukraine for the period up to 2020". № 880-r dated 17.10.2007.

Ruban L.I. Methodological foundations of architectural and landscape organization of coastal and water areas: author. dis. for science. degree of doctor of architecture: special 18.00.04, Kyiv: KNUBA, 2020. 26 p.

Samoilenko E.V. Problems of functional use of the city in the context of architectural and landscape organization of the river space. Urban planning and spatial planning. Kyiv: KNUBA, 2014. №53. Pp. 462-467.

Paris R. La valeur des delaissés. Catalog of the exposition of the Institute of French Architecture; L'Atelier La forêt des delaissés. 2000. P. 19-29.

Secchi B. Première leçond'urbanisme. Marseille: ÉditionParenthéses, 2006. 145 p. 


\section{AUTHOR'S NOTE}

Yevheniia Samoilenko - revitalization of urban spaces, green infrastructure of the city, riverside areas and methods of their development

Contact | Kontakt: jsamoilik@gmail.com 